\title{
DeSCIpher Undergraduate Sciences Competition: Reinventing Our Competition Online During COVID-19
}

Eun Young Bae, BHSc Student [1], Jessica Moreira, BHSc Student [2]*, Deep Shah, BSc Student [2], Gerthan Selvanathan, BSc Student [3], Abigail Jacob, BHSc Student [1], Shaheer Nadeem, BHSc Student [1], Renee Hu, BHSc Student [1], Aishwaria Maxwell, BHSc Student [1]

[1] Bachelor of Health Sciences Program, McMaster University, Hamilton, Ontario, Canada L8S 4L8

[2] Department of Biochemistry and Biomedical Sciences, McMaster University, Hamilton,

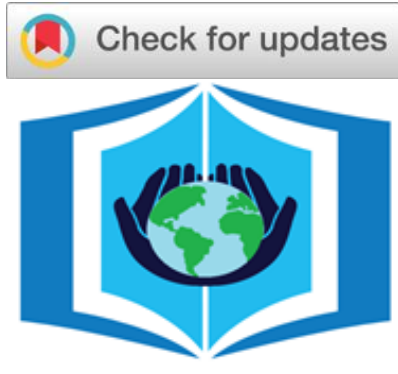

URNCST Journal

"Research in Earnest" Ontario, Canada L8S 4L8

[3] Department of Psychology, Neuroscience and Behaviour, McMaster University, Hamilton, Ontario, Canada L8S 4L8

*Corresponding Author: moreiraj@mcmaster.ca

\begin{abstract}
DeSCIpher: McMaster University Life Sciences Competition (MULSC) brings together undergraduate students of various science, technology, engineering, and mathematics (STEM) disciplines to collaboratively compete in a one-day competition. As one of McMaster University's largest science competitions, DeSCIpher aims to encourage interdisciplinary collaboration within the undergraduate community. This editorial will explore the changes that have been made to the competition since shifting to an online setting during COVID-19, specifically for the 2020-2021 academic year.
\end{abstract}

Keywords: DeSCIpher; case competition; scientific education; conference planning; online learning; virtual conference; COVID-19; innovation

\section{Introduction}

DeSCIpher: McMaster University Life Sciences Competition (MULSC) is a club organized by students highlighting McMaster University's commitment to knowledge and passion for the interdisciplinary sciences. Since its formation in 2016, DeSCIpher has brought together students of various science, technology, engineering, and mathematics (STEM) disciplines to collaboratively compete in an annual, one-day undergraduate competition.

\section{Leadership Structure}

The DeSCIpher Executive Team continues to be organized into specified committees that receive direct oversight from elected Co-Presidents. The committees open for selection in the beginning of the academic year and are chosen by October, and the new Executive Team works towards the annual competition which is held in January. These committees include the Research Committee; Logistics Committee; Marketing Committee; and Finance Committee. The internal election process for Co-Presidents occurs in March. The executives are considered on various merits, including commitment and teamwork, and in order to ensure longevity of the club, their undergraduate years are reviewed, as well.

Bae et al. | URNCST Journal (2021): Volume 5, Issue 7 DOI Link: https://doi.org/10.26685/urncst.284

\section{$\underline{\text { Co-Presidents }}$}

Once the Co-Presidents are elected each year, the planning for next year's competition begins immediately. In 2020, the uncertainty of whether in-person events would be permissible played a pivotal role in the planning process. Organizing a competition in an online setting that retained the unique features of DeSCIpher called forth new challenges. Improving the quality of the competition remains the main focus, and after assessing the available resources and personnel, the co-presidents recruit new executives. This extensive process involves an application that highlights the expertise of individuals from various disciplines and undergraduate years to guarantee the diversity and longevity of the club. Afterwards, the CoPresidents continue coordinating with the executives to ensure all tasks and responsibilities are appropriately handled. This is typically achieved through meetings and check-ins, both of which usually occur in-person. However, in considering the pandemic in 2020, all procedures for DeSCIpher were conducted online, requiring intensive agenda settings to keep track of planning and meetings.

\section{Research Committee}

The Research Committee aims to design questions for the competition. These questions of varying difficulties 
UNDERGRADUATE RESEARCH IN NATURAL AND CLINICAL SCIENCE AND TECHNOLOGY (URNCST) JOURNAL Read more URNCST Journal articles and submit your own today at: https://www.urncst.com

stem from six unique interdisciplinary categories: Anatomy and Physiology; Biology; Environmental Science and Geography; General and Organic Chemistry; Physics; and Psychology, Neuroscience and Behaviour. The executives consult reliable resources such as textbooks or academic literature, along with their existing knowledge to design questions. Subsequently, the research committee critically edits the questions for errors and incorporates feedback from other executives. During the competition itself, the research executives are responsible for the delivery of questions and for answering question-related inquiries from participants. In 2020, the questions were specifically designed to be a challenge in an online environment, shifting to incorporate more application-based questions rather than knowledge-based questions.

\section{Logistics Committee}

The logistics committee ensures the competition operates efficiently by performing various behind-thescenes tasks. This year, these executives played a critical role in exploring and designing the online platforms that would substitute the typical in-person format. They were responsible for devising anti-cheating methods to maintain academic integrity. Leading up to the competition, the logistics committee trained the other executives on the application of the newly integrated online platforms. This ensured that all members of the DeSCIpher Executive Team were properly equipped to answer questions and address technical difficulties during the competition.

\section{Marketing Committee}

The marketing committee acts as the liaison between DeSCIpher and the broader McMaster University community, including students, organizations, and faculties. They prepare promotional campaigns to raise awareness about DeSCIpher throughout the year. Furthermore, they build on the brand of DeSCIpher that was developed in previous years by creating more brand-aligned visuals and content. In preparation for the competition, these executives conduct marketing campaigns on accessible platforms, such as Facebook and Instagram. With help from other executive committees, the competition is promoted to numerous STEM faculties at McMaster University. Finally, the marketing committee continues to grow DeSCIpher's presence online through the club's website and social media.

\section{Finance Committee}

The finance committee works to budget and acquire necessary funds to run the competition and guarantee longevity of the club. They work with the logistics committee to ensure that all financial expenses are considered, including the usage of any paid online platforms. Various organizations and faculties across McMaster University are contacted for financial endorsements. Moreover, by endorsing local businesses, the executives establish mutually beneficial, long-lasting partnerships. Overall, the finance committee budgets any acquired funds for the year to ensure that DeSCIpher can run sustainably in the foreseeable future.

\section{In-Person Event Day Planning and Structure}

DeSCIpher has had an upward trend of participants since its inception in 2016, with hundreds of participants each year. Both individual and team registrations are accepted to encourage participation from all undergraduate years and programs at McMaster University.

When conducted in-person, the competition has both an Individual Round (where each participant demonstrates their unique problem-solving skills) and a Team Round (where members are encouraged to discuss with their team before presenting their answers). Every team is given a whiteboard and a marker to present their answers to the judge, a member of the DeSCIpher Executive Team, and points are granted to teams that answer correctly. The questions are delivered both in writing and through speech on smartboards with a countdown clock. Once the time is up, the teams are asked to present their responses and the correct answer is shown on the smartboard. There also exists a Jeopardy Round that utilizes a separate platform in order to mimic the Jeopardy structure, however altered to reflect the style of DeSCIpher's questions. The execution remains the same as that of the Team Round, with the participants being allowed to discuss with their team before presenting their answers.

The second half of the event day revolves around the Inquiry Challenge, meant to challenge students in demonstrating their teamwork, research, and critical thinking skills by proposing solutions to a pressing issue within society. Teams are given several hours to complete and submit their response to the DeSCIpher Executive Team, who then proceeds to grade each submission with a predetermined rubric as the judges.

Lastly, a Final Round is held for the top five teams from the Individual and Team Rounds to determine the final ranking. Prizes are then distributed at the Closing Ceremony.

There are several prizes that participants are able to win, with the details varying annually. Generally, DeSCIpher presents the $1^{\text {st }}, 2^{\text {nd }}$, and $3^{\text {rd }}$ Place Prizes to the team with the three highest points from the Individual Round, Team Round, and Final Round collectively. There is an Inquiry Challenge Winner granted to the team with the highest grade on their Inquiry Challenge submission, while the Jeopardy Round Winner is granted to the team who received the highest points from the Jeopardy Round. Lastly, DeSCIpher presents a Junior Team Winner which is granted to the team consisting of first and second-year undergraduate students with the highest points from the Individual Round, Team Round, and Final Round collectively. 
UNDERGRADUATE RESEARCH IN NATURAL AND CLINICAL SCIENCE AND TECHNOLOGY (URNCST) JOURNAL Read more URNCST Journal articles and submit your own today at: https://www.urncst.com

\section{Logistical Transition to Online Platforms}

Connecting Teams Through Zoom and Discord

The online setting of DeSCIpher's competition this year required the implementation of new platforms that connected the DeSCIpher Executive Team with participants. Zoom and Discord were integral in bringing everyone together, while ensuring teams could still connect with each other privately. Specifically, Zoom allowed everyone in the competition to have instantaneous communication with each other. Contrastingly, Discord allowed participants to interact with their teams through specific text and voice channels, as teamwork and communication were crucial for the competition's success. It also served as a method to reach any executives immediately for event day questions or technological concerns.

Running the two platforms simultaneously was important for the duration of the event day. For example, Discord provided the executives with a platform other than e-mail to relay important announcements or instructions to the participants during the event day itself, as it was challenging to correspond mass-announcements through Zoom with its chat-only feature. Using Zoom and Discord concurrently also allowed for DeSCIpher to create an anticheating platform, as the executives had access to Discord's text and voice channels assigned to each of the teams. This ensured that the participants were not interacting with individuals outside of the competition, and utilized Discord as their sole means of inter-group communication.

Overall, given the novel obstacles presented in the online setting, Zoom and Discord helped maintain the quality of the competition that was observed during previous in-person events. The online platforms ultimately provided a way for the teams to connect with each other without hindering their engagement with the rest of the competition.

\section{Trivia Platforms: Crowdpurr and TriviaMaker}

Due to the competition being held virtually this year, it was necessary to use online trivia platforms to aid in the delivery of questions. Specifically, Crowdpurr was used to supplement the Individual, Team, and Final Rounds of the competition and TriviaMaker was used during the Jeopardy Round. The logistics committee organized the training of other executives regarding how to navigate Crowdpurr and TriviaMaker, whilst the research committee inputted the questions and answers, and ran the online trivia platforms on event day.

Crowdpurr is an audience engagement platform that allows participants to join a virtual room from their electronic devices (i.e., mobile phones, tablets, computers) using a unique code. Once participants entered the virtual room, they had access to the questions, a space to type in their answers, and an in-game timer. During the Individual Round, all participants were asked to individually input their answers into Crowdpurr, which were then added to comprise the team's overall score. For the Team and Final
Rounds, only the team 'captain' was permitted to join Crowdpurr and input answers on behalf of their team after discussion. Care was taken to ensure that player and team rankings were not publicly displayed. However, to mimic the in-person competition, participants could see other inputted answers after a question timer ended.

TriviaMaker is an additional platform that was used as it has a unique Jeopardy-style grid layout. This software did not require participants to use their electronic devices to join a virtual room. Instead, the interactive grid was screen shared, and participants were able to verbally choose and answer questions after a short discussion period, similar to an actual game of Jeopardy. The software awarded points automatically to each team that answered a question correctly, and these points were displayed on the screen for all participants.

\section{Online Event Day Planning and Structure}

This year, the competition was tailored to an online setting through various mechanisms. As participants and executives were experiencing these changes for the firsttime, both parties were supplied with the resources needed to ease the transition. A competition information booklet was prepared for participants that outlined event day information, online etiquette, the itinerary, and instructions for using the online platforms. This was designed to reduce confusion and stress about how the competition would proceed in an online setting and was delivered to every participant in advance of the event day. Similarly, an information booklet was prepared for the executives, that included a detailed itinerary, along with specific tasks and responsibilities for each executive member throughout the competition. This ensured that all executives were familiar with their roles and would be well-equipped to handle any technical issues.

The event day started with a meeting for the executives, as a final briefing before the participants began joining Zoom. Once participants began entering, Live Captioning was turned on in Zoom. This ensured that the competition was as inclusive as possible in the online setting. Simultaneously, participants were registered as they were being admitted into Zoom, and the chat function was monitored to address any questions. Soon thereafter, the Opening Ceremonies began, and the executives were introduced, along with the itinerary for the event day. The Individual and Team Rounds followed on Crowdpurr. As the competition was held online, it was critical that break times were scheduled throughout the competition to avoid screen fatigue and burnout. Thus, an hour break for lunch and 10-minute breaks in between rounds were scheduled. In the afternoon, the Jeopardy Round and the Inquiry Challenge were conducted.

For the Inquiry Challenge, participants were given the opportunity to inquire about and derive solutions to a current issue in our society. This year, the Inquiry Challenge was centered around space debris - a pressing 
UNDERGRADUATE RESEARCH IN NATURAL AND CLINICAL SCIENCE AND TECHNOLOGY (URNCST) JOURNAL Read more URNCST Journal articles and submit your own today at: https://www.urncst.com

global concern. The prompt asked participants to formulate creative solutions to address the prevalence of space debris and present their researched information in the format of an infographic. Additionally, participants were asked to prepare a 200 -word abstract that could be published by The URNCST Journal, in the 'Abstract Book' for the DeSCIpher 2021 competition. Overall, participants were given until the end of the event day to research and prepare their two tasks in an eye-catching, informative, and wellreferenced manner.

The competition was extremely close this year after the Individual and Team Rounds. Thus, a Final Round was held, where the top-five teams competed in answering 12 tie-breaking questions. To end the competition, the Closing Ceremonies were held, where the executives thanked the sponsors, named the winning teams, presented the prizes, and reiterated gratitude for the support from the participants. Collectively, the competition was a great success, due in large part to the extensive preparation and dedication of the executives over the two semesters.

\section{Changes to Competition Structure due to the COVID-19 Pandemic and Goals for This Year}

Our main goal for this year was to maintain the engagement levels observed in-person, as we transition to an online setting due to the COVID-19 pandemic. Thus, all of the changes made this year kept this notion in mind, along with accounting for participants' feedback from previous years.

First, adjustments were made to the order of the rounds on event day. In previous years, participants suggested delaying the Jeopardy Round and having the Individual Round and Team Round together, instead of Individual Round, followed by Jeopardy Round, then the Team Round. As the shift in the style of rounds caused confusion and delays, the Jeopardy Round was kept separate this year. Particularly for the year 2020 as the competition was held online, this change allowed for a smoother transition between different online platforms.

Second, the duration of the competition was shortened by reducing the number of questions in each round. This addressed a previous concern when the competition deviated off-schedule.

Third, the competition categories were modified to better align with DeSCIpher's overarching goal of nurturing interdisciplinary collaboration. Specifically, the Immunology and Biology categories were combined and a new Environmental Science and Geography category was added. The newest addition appealed to a broader group of undergraduate students and increased the diversity of questions. This modification also addressed the participants' feedback about replacing the Immunology category. Moreover, the Biochemistry category was integrated under General and Organic Chemistry instead, alleviating concerns that stated the competition was too biologyfocused.

\section{Conclusions}

Challenges and Response to Challenges

Due to the ever-changing climate of the COVID-19 pandemic and the need to adapt to an online setting, the DeSCIpher Executive Team faced many new challenges with (i) integrity, (ii) streamlining multiple softwares, (iii) funding, and (iv) marketing. In retrospect, these challenges highlighted the importance of flexibility and adaptation.

One of the major challenges faced by the executives was preventing academic dishonesty. This involved ensuring that participants could not look up answers by using external resources or communicating with individuals outside of the competition. To accomplish this, the questions created by the research committee were more application-based than in previous years. Additionally, the questions were displayed through a Google Slides presentation on Zoom, rather than through Crowdpurr. This prevented the participants from pasting the questions directly into a search engine. Furthermore, Discord was specified to be the only acceptable means of communication for the teams during the competition. This allowed the executives to monitor the conversations and ensure that academic dishonesty was minimized.

Another difficulty was ensuring that the competition would run smoothly on the event day, given that multiple online platforms were utilized. The executives conducted many tests to ensure that the software would run without preventable technological issues. Initially, the viability of an online competition was tested using Crowdpurr and TriviaMaker. After these online platforms were deemed suitable, a 7-hour 'mock competition' was conducted with the executives to allow them to practice their roles for the competition. The mock competition was beneficial as it confirmed the time required for the rounds. Additionally, feedback could be provided instantly from the executives regarding roles and tasks.

Funding was also one of the prominent challenges when transitioning to an online setting. Once an appropriate budget was established, the finance committee reached out to local Hamilton businesses. Through correspondence with business owners, it became clear that many local businesses were in difficult financial situations and were unable to sponsor DeSCIpher this year due to the COVID-19 pandemic. In face of this adversity, DeSCIpher devised three solutions. First, the DeSCIpher Executive Team maintained connections with local businesses to allow for future endeavours. Second, funding was mainly sought from McMaster University Departments as they had augmented interests in supporting student-led events in lieu of the lack of social interactions due to the campus closure. Finally, these challenges inspired the executives to devise mutually beneficial and cost-effective sponsor relationships. For example, a partnership with StudyLamp, another student-led organization at McMaster University, was established. This partnership would benefit StudyLamp as awareness was raised for their club, whilst DeSCIpher 
was provided with StudyLamp subscriptions to be granted as prizes.

Lastly, there were many challenges in the marketing efforts to promote engagement from undergraduate students. Prior to the COVID-19 pandemic, lawn signs placed throughout the McMaster University campus were a critical method of developing brand awareness amongst undergraduate students, as documented from previous feedback. However, due to the transition to an online setting, physical marketing tactics were no longer a viable option. In response, the marketing committee worked to enhance DeSCIpher's online presence through a newly created Instagram account. To stimulate engagement and attract new followers, the executives organized weekly giftcard giveaways on the platform, concurrently introducing various DeSCIpher-formatted trivia questions. This platform will continue to be used as it was a great success in promoting the competition and club at large.

\section{Future Directions}

The online platforms that were used worked very well and exceeded expectations. With Crowdpurr, participants' scores were tracked with ease compared to previous years when this was done manually. Additionally, the in-game timer made the transition between questions more seamless and standardized the competition for the breakout rooms, providing all the participants with an equal opportunity to answer questions. The custom branding options available on Crowdpurr granted the ability to customize the look of the software, giving participants an air of familiarity with DeSCIpher's brand. With TriviaMaker, the Jeopardy gameplay style was emulated perfectly, which was not possible in previous years. Specifically, participants were able to see their scores live, allowing them to play strategically.

In the future, these online platforms could be integrated into the in-person competition. Having participants use their own electronic devices would substantially improve engagement levels, while the technological features alleviate several manual tasks for both the participants and executives. For example, the executives were previously responsible for providing participants with whiteboards and markers to submit their answers. Overall, the executives are hopeful in exploring these various online platforms and integrating them for future competitions to improve the delivery and quality of the DeSCIpher competition.

\section{Conflicts of Interest}

The authors declare that they have no conflict of interests.

\section{Authors' Contributions}

All authors contributed to the development and editing of the editorial.

\section{Acknowledgements}

The authors wish to acknowledge the incredible work of the last six DeSCIpher teams and the Editor, Jeremy $\mathrm{Ng}$, for his continued support of DeSCIpher and this editorial.

\section{Funding}

This study was not funded.

\section{Article Information \\ Managing Editor: Bi-Ru Amy Yeung}

Article Dates: Published Jul 2221

\section{Citation}

Please cite this article as follows:

Bae EY, Moreira J, Shah D, Selvanathan G, Jacob A, Nadeem S, Hu R, Maxwell A. DeSCIpher Undergraduate Sciences Competition: Reinventing our competition online during COVID-19. URNCST Journal. 2021 Jul 22: 5(7).

https://urncst.com/index.php/urncst/article/view/284

DOI Link: https://doi.org/10.26685/urncst.284

\section{Copyright}

(C) Eun Young Bae, Jessica Moreira, Deep Shah, Gerthan Selvanathan, Abigail Jacob, Shaheer Nadeem, Renee Hu, Aishwaria Maxwell. (2021). Published first in the Undergraduate Research in Natural and Clinical Science and Technology (URNCST) Journal. This is an open access article distributed under the terms of the Creative Commons Attribution License (https://creativecommons.org/licenses/by/4.0/), which permits unrestricted use, distribution, and reproduction in any medium, provided the original work, first published in the Undergraduate Research in Natural and Clinical Science and Technology (URNCST) Journal, is properly cited. The complete bibliographic information, a link to the original publication on http://www.urncst.com, as well as this copyright and license information must be included. 
UNDERGRADUATE RESEARCH IN NATURAL AND CLINICAL SCIENCE AND TECHNOLOGY (URNCST) JOURNAL

Read more URNCST Journal articles and submit your own today at: https://www.urncst.com

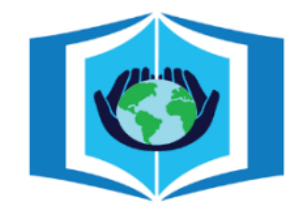

\section{URNCST Journal \\ "Research in Earnest"}

\section{Funded by the Government of Canada}

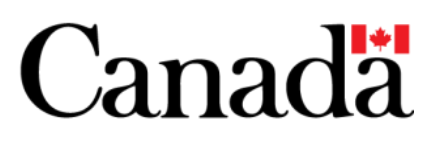

Do you research in earnest? Submit your next undergraduate research article to the URNCST Journal!

| Open Access | Peer-Reviewed | Rapid Turnaround Time | International | | Broad and Multidisciplinary | Indexed | Innovative | Social Media Promoted |

Pre-submission inquiries? Send us an email at info@urncst.com | Facebook, Twitter and LinkedIn: @URNCST Submit YOUR manuscript today at https://www.urncst.com! 